\title{
Dimensões dos conflitos territoriais do Brasil - Quilombos e Território
}

\author{
Dimensions of territorial conflicts in Brazil - Quilombos anda \\ Territory \\ Dimensions des conflits territoriaux au Brésil - Quilombos et \\ Territoire
}

\author{
Lourdes Carril \\ lourdescarril@ufscar.br \\ Professora da Universidade Federal de São Carlos _ UFSCar, campus Sorocaba \\ https://orcid.org/0000-0001-9054-6880
}

\section{RESUMO}

Neste trabalho, buscamos refletir sobre as dimensões dos conflitos territoriais no Brasil a partir dos territórios quilombolas. Sobre perdas e ressignificações que ensejam resistências históricas ao desaparecimento, agora frente à urbanização e seus conteúdos recentes que avançam sobre o campo e a cidade, sob a forma de condomínios fechados, em espaços da Região metropolitana de Sorocaba. A história da formação territorial brasileira é marcada por lutas e violências contra os povos que formam a sociedade. $O$ debate é concernente à construção do Estado nacional e seu território à maneira colonialista do poder. Entendemos que essa formação é até hoje profundamente marcada por séculos de escravidão, seguidos por estratégias estatais e privadas, cujos fundamentos operam segundo um território branqueado, articulado/inseparável e prenhe de riquezas a serem expropriadas e exploradas. $\mathrm{O}$ projeto se dá pelo descolamento do mundo vivido por inúmeros grupos sociais, modos de vida, territórios étnicos e singulares e de relações sociais culturalmente constituídas, comportando a dinâmica da totalidade social, natureza, vida e trabalho, símbolos e representações.

Palavras-Chave: Conflitos Territoriais, Quilombos, Território Branqueado, Urbanização

\begin{abstract}
ABSTACT
In this work we intend to think over the dimensions of the territorial conflicts in " quilombola» lands in Brazil. They refer to losses and new meanings which have led to historical resistance against their disappearance. Nowadays they have faced urbanization and its recent contents spread over the country and the cities in the shape of closed condominiums in Sorocaba's metropolitan region. The territorial formation in Brazil is marked by struggles and violence against the people who form Brazilian society. This debate concerns to the construction of the National State and its territory by means of the colonial imposition of power. We understand that such formation has been marked by centuries of slavery until today, followed by public and private strategies, whose fundaments operate according to a whitened territory, articulated inseparably and full of richness to be expropriated and exploited. This project occurs by means of dissociating a great number of social groups from the world they live - their ways of living, their ethnic and singular territories showing dynamics of social totality, nature, lives and work, symbols, and representations.
\end{abstract}

Keywords: Territorial Conflicts, Quilombos, White Territories, Urbanization 


\section{RESUMÉ}

Notre proposition est de de réfléchir sur les dimensions des conflits territoriaux au Brésil à partir des territoires quilombolas. Sur les pertes des resignifications qui suscitent des résistances historiques à la disparition, et face à l'urbanisation et à ses contenus récents qui avance sur la campagne et la ville, sous forme de copropriétés fermées, dans les espaces de la région métropolitaine de Sorocaba. La formation territoriale brésilienne est marquée par des luttes et des violences contre les peuples qui composent la société. Le débat porte sur la construction de l'État national et de son territoire à la manière colonialiste du pouvoir. On comprend que cette formation est encore profondément marquée par des siècles d'esclavage, suivis de stratégies étatiques et privées, selon un territoire blanchi, articulé/inséparable, et regorgeant de richesses à exproprier et à exploiter. Le projet se déroule à travers la séparation du monde vécue par d'innombrables groupes sociaux, modes de vie et territoires ethniques, comprenant la dynamique de la totalité sociale, la nature, la vie et le travail, les symboles et les représentations.

$\begin{array}{llr}\text { Mots-clés: } & \text { Conflits } & \text { territoriaux, } \\ \text { Quilombos, } & \text { territoires } & \text { blanchis, }\end{array}$

Urbanisation.

territoires blanchis,




\section{Introdução}

"Nós queremos o território livre" (MIQCB e quilombolas de Sesmaria do Jardim) ${ }^{1}$

"Não queremos que os territórios indígenas sejam no futuro favelas sem-terra, sem riqueza e sem ter o que comer" (Elcio Severino Manchineri, da Coordenação das Organizações Indígenas da Amazônia Brasileira) ${ }^{2}$

Diversos conflitos territoriais brasileiros passam pelo enfrentamento a lógicas socioespaciais que comportam, sobretudo, a questão da propriedade privada implicada nas geopolíticas que articulam Estado, mercado e território. Os impactos sobre territorialidades diversas, abrangendo indígenas, caboclos, pescadores artesanais, comunidades de quilombos, seringueiros e muitos outros grupos, têm sido estudados sob diversas categorias, como "comunidades", "povos", "culturas", as quais se fazem acompanhar de nomenclaturas, também, de "povos tradicionais" no âmbito dos tratados e convenções ambientais internacionais. Sendo a vida no território elemento fundamental para abarcar a relação com a terra, os recursos, a tradição e a reprodução da vida, observamos que é no seio do embate entre mercantilização dos fundos territoriais e a (re) existência que se fortalecem vínculos com o passado. Neste trabalho, buscamos refletir sobre dimensões dos conflitos territoriais no Brasil a partir dos territórios quilombolas. Sobre perdas e ressignificações que ensejam resistências históricas ao desaparecimento, agora frente à urbanização e seus conteúdos recentes que avançam sobre o campo e a cidade, na forma de condomínios fechados, em espaços da Região metropolitana de Sorocaba3.

A comunidade quilombola Fazendinha de Pilar, em Pilar do Sul, sudoeste do Estado de São Paulo (Figura 1), luta há mais de um século para garantir seu direito territorial. Com o falecimento dos senhores escravistas, o Tenente Antônio de Almeida Leite e sua esposa Maria Vieira Sant'Ana, na segunda metade do século XIX, os seus antepassados receberam terras em doação feita em testamento pelo casal, com a condição de que as terras não fossem vendidas em tempo nenhum. Vogt \& Fry (1996), estudando a estrutura linguística (a "cupópia”) da comunidade de Cafundó, em Salto de Pirapora, perceberam que foi marcante esse processo de doações de terras de senhores a seus escravos na região, sendo este elemento, analisado pelos autores a partir de seu caráter contraditório, pois poderia expressar uma estratégia de controle das tensões existentes no cenário escravista, ao mesmo tempo em que favorecer famílias com a posse da terra. Apesar de novas contradições se apresentarem, hoje, é evidente que a demanda territorial feita pela comunidade, que se encontra dispersa no espaço urbano, vem a se fortalecer com o momento da doação, a partir de memória oral e documental, organizada e cuidada pelas gerações dos mais velhos que se vão, mas que são legadas às nova gerações.

\footnotetext{
${ }^{1}$ https://www.miqcb.org/post/n\%C3\%B3s-queremos-o-territ\%C.3\%B3rio-livre-miqcb-e-quilombolas-desesmaria-do-jardim-se-re\%C.3\%BAnem-com-a-saf

${ }^{2}$ https://www.camara.leg.br/noticias/750935-indigenas-discordam-sobre-regulamentacao-de

3 Este artigo é parte do desenvolvimento da pesquisa "Perdas e Ressignificações dos Usos do Território na História do Negro em Sorocaba" - Chamada: Chamada MCTIC/CNPq No 28/2018 - Universal.
} 
Figura 1 - Localização de moradias quilombolas na cidade Pilar do Sul, com destaque para a Associação dos Remanescentes do Quilombo do Espólio do Tenente Almeida Leite - Fazenda Pilar - Pilar do Sul/SP

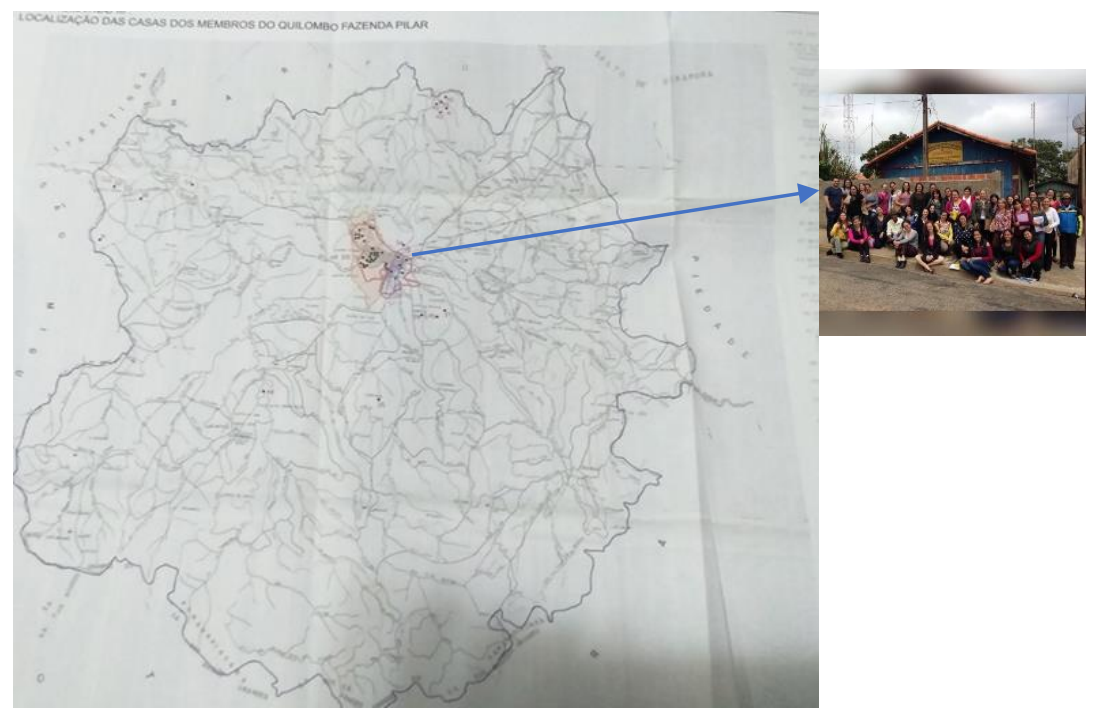

Fonte: RTC - Relatório Técnico Científico - ITESP e Foto da Autora ${ }^{4}$

Vê-se, assim, em tais processos a demonstração de significados do viver territorial para grupos que, entre o final do século XX e o de XXI, se auto identificam com base nas condições sociais, culturais e econômicas, distintas de outros domínios da coletividade nacional5. Contudo, a pluralidade dos grupos, não somente é pertinente à sua multidimensionalidade, mas se mostra bastante ampla internamente aos próprios segmentos, como são o caso dos quilombolas localizados em distintos espaços brasileiros. Os vínculos com o trabalho, terra, natureza e cultura, estão presentes nos territórios quilombolas, o que requer da análise geográfica a consideração de diferentes modos de organização social dos grupos formados por comunidades negras distribuídas no território nacional.

As categorias espaço e território são caras à ciência geográfica, seus sentidos e conceituação têm se ampliado à medida em que a realidade socioespacial brasileira impõe desafios complexos com a presença de novos personagens envolvidos nas teias conflituosas da modernização do território brasileiro. A novidade, na verdade, não é isenta da historicidade da formação social, pelo contrário, ela revela continuidades e descontinuidades do processo histórico. Nesse caminho de método, é a totalidade da vida social quem nos encaminha a pensar as duas categorias geográficas, a partir de reflexões realizadas e extremamente importantes a elas.

Os processos geográficos são relações sociais porque contêm as intencionalidades que produzem formas e conteúdos espaciais, segundo

\footnotetext{
4 Figura construída a partir do croqui de localização das moradias presente Relatório Técnico-Científico sobre os Remanescentes da Comunidade de Quilombo "Tenente Antônio de Almeida Leite", Fazenda Pilar/Pilar do Sul/SP - ITESP, 2007, e da foto da Associação Quilombola tirada pela autora (2016).

5 Vale dizer que o reconhecimento dessa diversidade é estabelecido internacionalmente (Convenção $\mathrm{n}^{\circ} 169$ da OIT sobre Povos Indígenas e Tribais de 1989). No seu Artigo $2^{\circ}$ consta: "como responsabilidade do Estado envidar ações de proteção aos povos tribais e comunidades indígenas: 1. Os governos deverão assumir a responsabilidade de desenvolver, com a participação dos povos interessados, uma ação coordenada e sistemática com vistas a proteger os direitos desses povos e a garantir o respeito pela sua integridade”. Esta recomendação foi acolhida pelo Decreto 4887/03, que instituiu a autoidentidade aos grupos que vão demandar o reconhecimento territorial.
} 
temporalidades diversas, integrando natureza, espaços, lugares, territórios, regiões e paisagens (SANTOS, 1996). A questão inerente ao espaço, contudo, não se resume às ciências, pois ela é parte substantiva do ser no processo antropológico da longa separação da natureza. Processo este que ocorre numa maior magnitude na modernidade contemporânea quando mediações mais complexas se interpõem nos espaços tornando-os mais estranhos aos grupos e às suas sociabilidades, bem como dificultam a recomposição de seu domínio junto à natureza, cada vez mais instrumentalizada pela racionalidade econômica. A produção e o conhecimento do espaço, portanto, são fundamentais à vida; apropriação das qualidades espaciais fazem parte do processo histórico da formação do humano; as relações espaciais constituem, assim, diversas territorialidades, resultado de saberes e estratégias ampliadas frente à sobrevivência.

Nesse sentido, o conceito de multiterritorialidade é importante referência teórica para a análise das problemáticas apresentadas, seja pela realidade social, academia, planejamento estatal e outros (HAESBAERT, 2014, p. 56), seja pelas diversas lógicas territoriais comunitárias que se apresentam. Segundo o autor, sempre houve a pluralidade de territórios múltiplos, o importante, então, no atual momento da modernidade, seria analisar as relações, não somente entre os limites próprios às territorialidades, mas, também, às sobreposições conflituosas que se estabelecem:

É como se fossem duas perspectivas distintas: na primeira, o olhar vai mais dos limites do "território plural" para o seu interior, na segunda o olhar prioriza as relações deste território com aqueles que se encontram para além ou "acima" dele. Tanto num caso como no outro o convívio de múltiplas territorialidades implica sempre disputas (HAESBAERT, 2004, p. 20)

Raffestin (1993) analisa território como uma condição inerente à espécie humana, no sentido que cada um, ou qualquer coletividade, desenvolve um conjunto de relações com a alteridade por meio de mediadores ou instrumentos: o espaço, para o autor, seria, assim, a "condição original, ou prisão original, primária, e o território é a prisão que os homens constroem para si". Nessa assertiva, encontramos a possibilidade de pensar que as espacialidades modernas são base para a sua própria negação pelas territorialidades subjacentes que a todo momento surpreendem com estratégias importantes à sobrevivência face às descontinuidades da modernização em espaços periféricos, como é o Brasil. Em A Natureza do Espaço, Santos (1996, p. 271), afirma que "a noção de territorialidade é colocada em xeque" pelas redes que se utilizam de todos os territórios, contudo, o autor enfatiza que a produção de normas, no momento atual, se torna mais forte a partir do papel do Estado como regulador dos poderes em seus diversos níveis. Nesse sentido, ele reafirma a importância do território como totalidade social para a reflexão das distintas e complexas lógicas dos lugares em face da mundialização dos eventos. Essa configuração territorial seria pertinente aos processos históricos e aos pactos territoriais que, no caso brasileiro, se apresentam como específicas ações em torno do território.

Ao produzirem seus espaços e neles se realizarem, as relações sociais também são produzidas pelos espaços. Segundo Lefebvre (2001), é o que ocorre, também, no urbano, este que se autonomiza da história industrial e passa a comportar estruturas que avançam independentemente da indústria. Este pode ser o caso da financeirização do território urbano, que, na contemporaneidade, se 
instala cada vez mais submetendo a indústria, o consumo, a vida e o espaço urbano.

Em Sorocaba e região, a reestruturação produtiva ocorrida a partir da metrópole paulista acarretou a migração de indústrias para lá, a partir da década de 1990, quando a economia paulista veio a responder, mais efetivamente, às políticas econômicas de caráter neoliberal, com impactos sobre o mundo do trabalho e, também, com a produção de novas centralidades urbanas (SPOSITO, 2015). Neste sentido, o planejamento de Estado fora cada vez mais abandonado, bem como também a dimensão regional deixou de fazer parte das ações dos governos nacionais. Como resultado, não apenas houve uma menor expansão econômica do país, como também acentuação das desigualdades regionais. Esse movimento de descentralização das indústrias da capital se dá em direção ao interior do Estado de São Paulo, principalmente, nos municípios limítrofes aos principais eixos rodoviários num raio de $150 \mathrm{Km}$ partindo da capital, particularmente, ao longo das rodovias Anchieta, Imigrantes, Dutra, Bandeirantes, Anhanguera e Castelo Branco. Lencioni (2003, p. 465) analisa que esse foi um processo de cisão territorial da indústria e de integração regional do Estado de São Paulo, em que a estratégia territorial das empresas industriais procurou separar em municípios distintos, a planta industrial, da gestão empresarial. Isto acabou por evidenciar, segundo a autora, a relação entre os lugares configurando uma regionalização deste processo, e constituindo uma forma urbana ainda mais densa e concentrada territorialmente, identificada como um aglomerado metropolitano que anuncia a formação em curso de uma megalópole. $\mathrm{O}$ processo verificado, atualmente, em curso na região metropolitana sorocabana, é o de aceleração da urbanização que destaca a acumulação de distintas fases de expansão urbana, comportando a presença não harmônica de "territórios plurais": territórios industriais, especulação imobiliária, condomínios fechados, municípios ruralizados, territórios cada vez mais dispostos aos vetores, tanto metropolitanos paulistas, quanto internacionais, e territórios quilombolas, indígenas, periféricos etc.

Importante ressaltar que os processos econômicos e mercadológicos avançam com a criação da Região Metropolitana de Sorocaba ${ }^{6}$, provocando mudanças e pressões sobre os territórios a ela integrados. Vale lembrar a análise que Moraes realiza sobre as formulações de Milton Santos a respeito do papel que a cidade assume como representante do "capital geral", e que na etapa da construção de regiões metropolitanas, equivaleria a "entender as regiões metropolitanas como respostas à necessidade de ampliação do capital" (MORAES, 2013, p. 76)

A indissociabilidade de agentes históricos em relação às problemáticas dos espaços promove, assim, os movimentos dos espaços sociais e a ressignificação contínua dos territórios. Esses movimentos que acentuam as propriedades dos espaços e a ressignificação de territórios são manifestadas em ações, relações e expressões, materiais e imateriais: ribeirinhos, quilombolas,

6 A Região Metropolitana de Sorocaba (RMS) foi institucionalizada em 8 de maio de 2014 pela Lei Complementar Estadual $n^{0}$ 1.241. É composta por 27 municípios, agrupados em três sub-regiões:

- Sub-região 1: Alambari, Boituva, Capela do Alto, Cerquilho, Cesário Lange, Jumirim, Sarapuí, Tatuí, Tietê e Itapetininga.

- Sub-região 2: Alumínio, Araçariguama, Ibiúna, Itu, Mairinque, Porto Feliz, Salto e São Roque.

- Sub-região 3: Araçoiaba da Serra, Iperó, Piedade, Pilar do Sul, Salto de Pirapora, São Miguel Arcanjo, Sorocaba, Tapiraí e Votorantim. Ver: Plano de Desenvolvimento Urbano Integrado - Região Metropolitana de Sorocaba. Disponível em: https://www.pdui.sp.gov.br/sorocaba/?page id=56. Acesso em: 11 nov. 2021. 
quebradeiras coco de babaçu etc., nas regiões brasileiras. Ou seja, trata-se de representações que extrapolam as próprias fronteiras interestaduais e os próprios sujeitos envolvidos, no caso da Amazônia (ALMEIDA, 2004), sendo que a sua construção tem se remetido a vínculos comunitários e símbolos que permeiam a história e a tradição. Para uma análise geográfica da formação territorial, aqui lançaremos mão da noção de território étnico para analisar a construção de múltiplas territorialidades que se manifestam sob formas similares e distintas, em espaços diversos, a partir das lutas originadas desde séculos de escravidão, os quais deixaram marcas de desigualdades e lutas com base nas relações étnicas e raciais, como são os quilombos na região de Sorocaba.

Essa diversidade, se apresenta, conforme Gomes (2015), pelo fato, também, de que os quilombos brasileiros se remetem a historicidades pertinentes ao período colonial e ao Império, e não necessariamente correspondendo ao modelo de quilombo fugas. Eles demonstram diversas origens que se apresentam nas memórias e nos documentos históricos locais. Em Sorocaba, muitos territórios se originam com base em doações de antigos senhores, mas verificamos, em outras localidades brasileiras, territorialidades constituídas após abandono dos escravos em lugares de economia decadente, terras doadas a santos e igrejas etc. Por sua vez, representam inúmeras e distintas relações intrínsecas aos locais onde se formaram, próximos às fazendas e senzalas, envolvendo comerciantes e até senhores de fazendas, contrariando a noção de isolamento como marca da vida dos aquilombados, pois conexões envolvendo grupos de diversas origens ocorriam, nas áreas rurais, nos rios, e nas proximidades de centros urbanos. Finalmente, destaca o autor que a diversidade de meios geográficos se entrelaça a um continuum/descontinuum (grifo nosso) das práticas quilombolas ensejando formas de organização da vida dos grupos com base na economia desenvolvida, seja em torno da agricultura camponesa, pesca, extrativismo, cultura caipira do interior paulista, nordestino e muitas outras presentes.

\section{Territorialidades quilombolas na RMSP}

A história quilombola na região metropolitana de Sorocaba demonstra sua origem comum a partir da escravidão em áreas que, por muito tempo, corresponderam à maioria dos atuais municípios os quais, inclusive, se integram, hoje, a essa organização territorial. Sorocaba, no período colonial era "boca de sertão"7, a área de entrada do processo de ocupação e exploração da região conhecida como "sertão desconhecido", por onde frentes bandeiristas, de aprisionamento e escravização indígenas e suas frentes econômicas vão incorporando escravos negros (BACELAR, 2020). As territorialidades quilombolas, atualmente, despontam em vários dos municípios partícipes da região metropolitana, demonstrando, também, no período atual, que há intrínsecos vínculos familiares entre os quilombos e destes com as famílias proprietárias de escravos, cujas ascendências remontam aos grandes sesmeiros de então.

\footnotetext{
7 Ver: MAIA, Doralice Sátyro. A ferrovia nas cidades bocas de sertão Alterações na morfologia e na estrutura urbana. Terra Brasilis (Nova Série), 8 | 2017.

Disponível em: <https://journals.openedition.org/terrabrasilis/2160 > Acesso em: 10 nov. 2021.
} 
A comunidade quilombola urbana de Fazendinha Pilar se localiza na cidade de Pilar do Sul, (Mapa 1), reivindica o território, remontando ao período de 1815 a 1842, quando o Tenente Antônio de Almeida Leite e sua esposa Maria Vieira Sant'Ana adquiriram do Tenente Coronel Bento Gonçalves de Oliveira um pedaço de terra correspondente a 3 mil alqueires e denominaram Fazenda Pilar. Estabeleceram ali moradia para si e os escravos, produzindo na terra agricultável e criando animais. Após o falecimento do Tenente, ele deixa em testamento a posse da terra aos escravos das terras, lavrado em 20 de janeiro de 1866, quatro anos antes de sua morte. As condições expressas são que "as terras não sejam vendidas em tempo nenhum, para que se criem seus filhos e netos, mesmo sendo campo ou mato a Fazenda Pilar. Os escravos são: Ana, Antônio, Catarina, Cristina, Eva, Francisco, Isidoro, Lourenço, Manoel, Manoel Paulo, Olímpia e sua filha Francisca, Procópio, Rita, Salvador, Tereza e Verissimo (...) Todos os dezessete escravos do Tenente Almeida Leite foram enganados por coronéis e capitães da época em conluio com os escravos mais espertos, tendo ocorrido fraude na aquisição de partes da Fazenda Pilar em troca de 'quinquilharias'”8.

Mapa 1 - Padrões Socioespaciais na RMS.

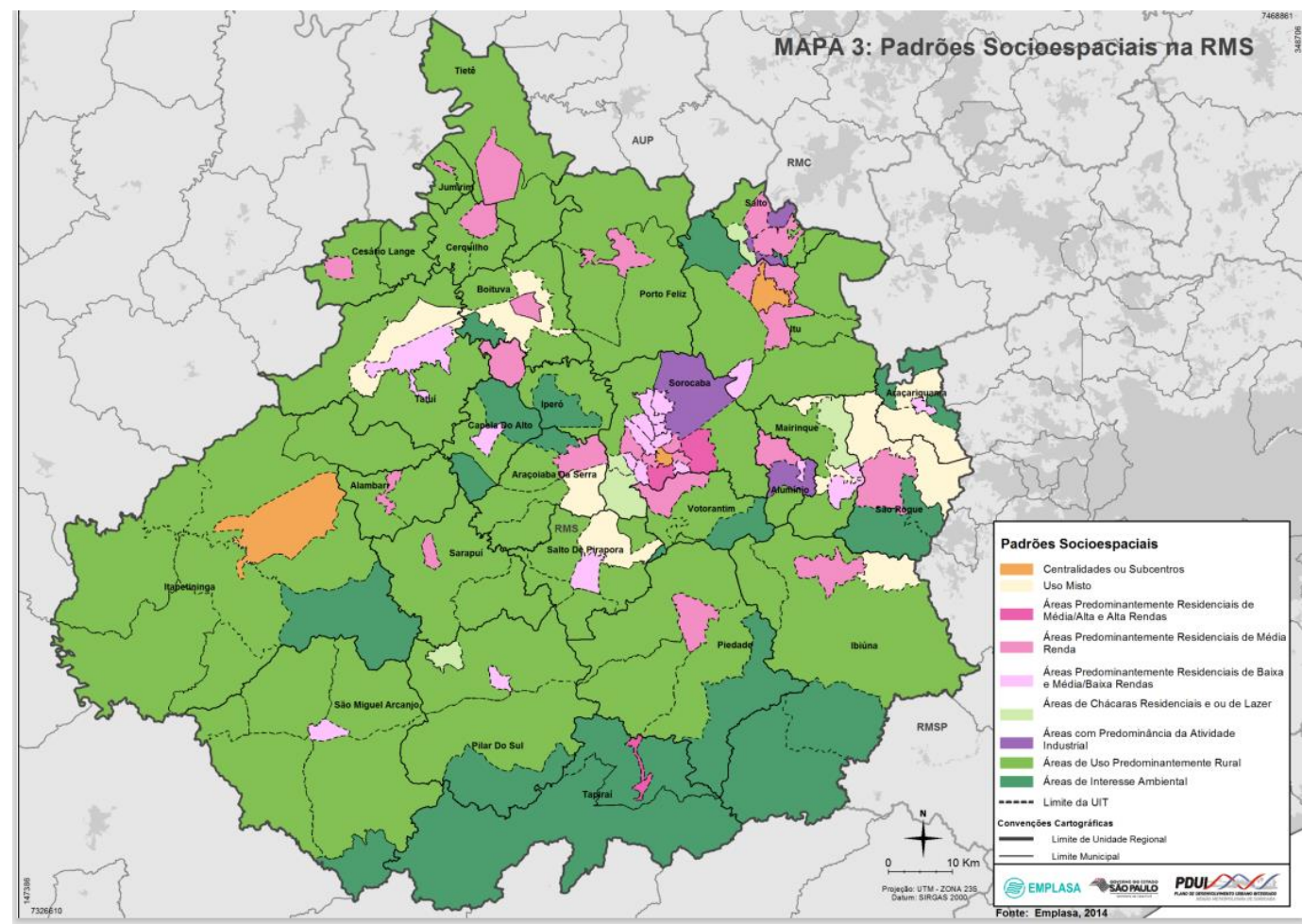

Fonte: https://www.pdui.sp.gov.br/sorocaba/?month=jul\&yr=2017

Segundo Vieira (2012, p. 09):

(...) a família Almeida, descendente do escravo Lourenço e Eva de Almeida (citados no testamento aberto do Tenente Almeida), após a morte do Tenente e leitura do testamento ficaram com as terras a eles descritas, como eram casados não perderam o direito as terras, visto que o casamento entre escravos e branco caracterizava segundo o testamento em perca (sic) do direito a terra. Porém, com o passar dos anos, os

\footnotetext{
${ }^{8}$ Segundo consulta ao Blog Quilombo do Pilar “A verdadeira história do quilombo de Pilar do Sul”. Segundafeira, 10 de dezembro de 2012. Disponível em: <https://quilombodopilar.blogspot.com/>Acesso em: 29 out 21.
} 
brancos invadiram as terras deixadas para os negros, através de mudança de cercas e apropriações inadequadas. Em 1899, o Coronel José Batista, presidente da Câmara Municipal, comprou do escravo Mateus as terras a ele deixadas. No entanto, "eles se apropriaram duas vezes de 'má fé'. $1^{\mathrm{a}}$. em testamento, o Tenente não autorizava a venda de terras por parte dos beneficiados. $2^{\circ}$. A Câmara documentou que a compra feita foi outra ao invés de colocarem também mais 9 alqueires do lado do que pertencia ao escravo Lourenço". Assim, o processo de perda das terras continuou no século XX, pois, durante o mandato do Prefeito Antônio José Ayub, em 1977, a Prefeitura teria utilizado de documentação para entrar com pedido de desapropriação das terras da Fazenda Pilar, que pertenceriam à Prefeitura Municipal. Mandou-se, então, uma carta de desocupação da área acompanhada de policiamento.

Segundo a autora, a partir de 1977, quando o então prefeito solicitou a desapropriação das terras, os descendentes passaram a pensar em uma maneira legal de obter as terras de volta. Famílias se reuniram para reivindicar seus direitos junto aos órgãos competentes, num período que ainda não tinham organização com amparo legal. Em 2003, com o Decreto 4887/o3, deu-se a possibilidade de autodeclaração. A Fundação do Instituto de Terras do Estado de São Paulo "José Gomes da Silva" (ITESP) concluiu o levantamento das terras em 28 de julho de 2007, com planta e memorial descrito na área de 547,0113 hectares ou 226 alqueires de terra, reconhecendo o território e encaminhando ao INCRA - Instituto Nacional de Colonização e Reforma Agrária, para a titulação9.

As perdas territoriais quilombolas em Sorocaba são históricas e a urbanização é um dos processos principais, junto a outros, como grilagens que incidem sobre os territórios da Fazenda Pilar. Nesse sentido, é importante analisar a dinâmica que hoje está presente a partir da reestruturação produtiva da metrópole paulista, acarretando o avanço da urbanização nos municípios da Região Metropolitana, bem como a formação de periferias que apresentam porcentagem elevada de famílias negras (Mapa 2). Interpretamos que esse fenômeno pode ser compreendido como dinâmica integrada ao espaço em transformação recente, portanto, articulada, tanto ao processo histórico que teve como contrapartida a escravização do negro quanto às novas frentes que avançam na região metropolitana, concorrendo cada vez mais para aumento dos fluxos migratórios no sentido do espaço urbano sorocabano.

Sorocaba se caracteriza como uma cidade paulista, não muito distante da metrópole nacional, no contexto da denominada macro metrópole paulista. Com seus mais de 600 mil habitantes, ela se projeta como polo atrativo para setores produtivos - a exemplo do já consolidado distrito industrial do Éden, desde os anos 1970, e pelo eixo mais recente de investimentos em torno do Parque Tecnológico e da multinacional Toyota no extremo noroeste da mancha urbana do município. A formação de suas periferias urbanas é uma faceta historicamente recente, caracterizando-se como uma das formas urbanas de segregação. No tempo histórico de mais longa duração, encontra-se em Sorocaba e região os marcos territoriais da presença quilombola que, igualmente, desvela as relações sociais pretéritas marcadas pela desigualdade e opressão étnico-racial (CARRIL, BURGOS, 2020).

\footnotetext{
9 Relatório Técnico Científico (RTC) sobre os Remanescentes da Comunidade de Quilombo "Tenente Antônio de almeida Leite”. Fazenda Pilar/Pilar do Sul-SP. ITESP, setembro 2007.
} 
As novas funções do espaço metropolitano paulista constituíram-se com a reestruturação urbana na passagem de metrópole industrial para a metrópole terciária e com feições globais e o processo de descentralização industrial levou interesses sobre espaços do chamado Interior Paulista. Ao considerarmos a produção das desigualdades espaciais urbanas, os lugares demarcam relações intrínsecas às estruturas e forças econômicas capitalistas que tornaram viável o processo de valorização do espaço, em novos patamares que requerem a atuação do Estado para a realização de novos espaços racionais-funcionais e das estratégias do capital financeiro na metropolização contemporânea (CARLOS, 2004). Mas, também, verificando-se que os agentes locais e globais passam a atuar diretamente em lugares impondo, assim, dinâmicas socioespaciais e mudanças às paisagens urbanas. Sorocaba e os demais municípios de sua região comportam a chegada de formas urbanas cujos conteúdos evidenciam a presença de elementos segregadores, como são os condomínios fechados e ao mesmo tempo já apresentam tendência à espacialização apartada de famílias negras que, ao longo do tempo, vêm sendo deslocadas de seus antigos territórios e passam a integrar periferias, reproduzindo um fenômeno característico da urbanização brasileira (mapa 2).

Mapa 2 - Segregação socioespacial e racial em Sorocaba.

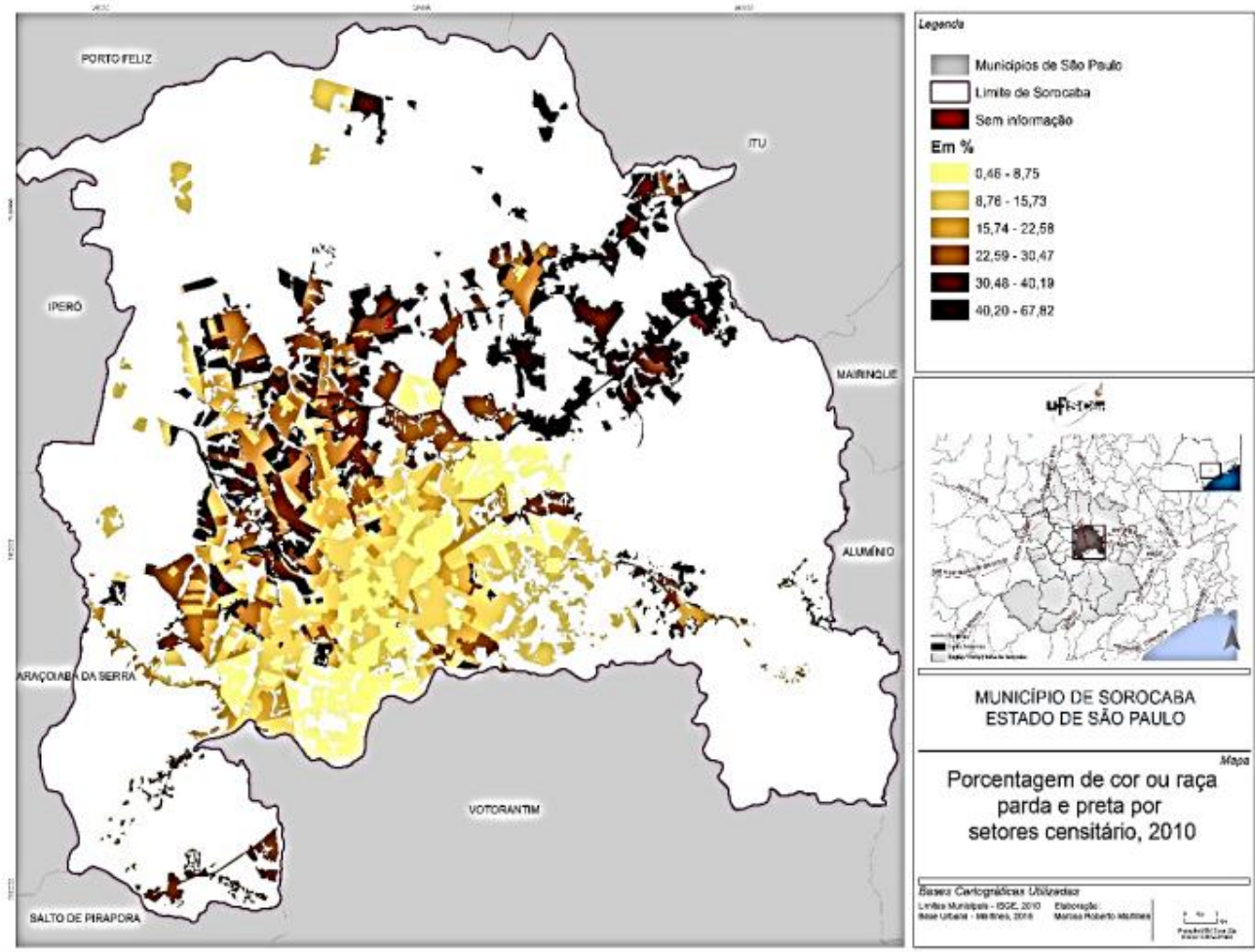

Autor: Marcos Martines (UFSCar, campus Sorocaba, 2017)

O mapa 2 apresenta maiores concentrações de famílias negras na região norte de Sorocaba, considerada, atualmente, uma região periférica por constituir espaços nítidos de segregação socioespacial. Embora a comunidade Fazenda Pilar, Cafundó e outros territórios quilombolas se localizem em outros municípios, na pesquisa em andamento, estamos tecendo a hipótese de que a dinâmica territorial racial brasileira, capitaneada pela urbanização 
contemporânea, compreende fluxos de migração e apartamento socioespacial, sobretudo, pela busca de trabalho e moradia, nas adjacências dos territórios quilombolas, mas também, em áreas urbanas próximas ou distantes. A análise sobre a regularização dos territórios quilombolas, presentes na RM de Sorocaba, demonstra que a pendência de titulação e o não reconhecimento de alguns territórios e escassas políticas públicas de assistência técnica e financeira, apontam para amplitudes de periferização concreta, fenômenos para os quais ainda não temos conclusões finais dado o estágio de desenvolvimento da pesquisa.

\section{Formação Territorial Brasileira e Branqueamento do Território}

Desde o final do século XIX, observa-se legislação que regulamenta as terras indígenas e suas relações com o Estado $^{10}$. No caso dos antigos quilombos que fizeram parte da história de resistência à escravidão, nada foi apresentado como forma de estabelecimento de seus direitos enquanto trabalhadores livres, tampouco a indenização pelos séculos de trabalho escravo; além disso, não foram reconhecidos seus territórios, sendo considerados, ao contrário, páginas viradas após a abolição da escravidão.

Nesse sentido, a construção do Estado nacional pode ser entendida sob discursos ideológicos geográficos, cujas representações do Estado, da Nação e do Território, serão tomadas hegemonicamente, conforme o padrão ocidental. A modernização brasileira e a colonialidade do poder ${ }^{11}$ que lhe é característica se seguiu após a Independência, em 1822, em contextos de "descolamento entre o mundo das ideias e o mundo da vida prática brasileira” (MORAES, 2002, p. 41). Tal visão é de espaço homogêneo, vazio e a natureza, portanto, matéria prima subserviente às demandas produtivas e econômicas (CORREA, 2013). São, assim, estabelecidas práticas espaciais sem vínculo com o lugar e o cotidiano das comunidades e pequenos lavradores, homens livres, forros ou escravos, ou como são os quilombolas e os indígenas, e diversas populações, que reproduzem seus modos de vida em diversos ecossistemas brasileiros, há muito tempo.

As geopolíticas que gestam e gerem o processo de integração nacional vieram a compreender o território brasileiro como um espaço a ser ocupado, indicando a permanência da concepção do território como reserva de riquezas a

\footnotetext{
${ }^{10}$ Segundo Azanha (2001): "O artigo 72 do Regulamento no 1318 de 1854 (que manda executar a Lei de Terras) determinava que fossem reservadas das terras devolutas aquelas necessárias para colonização e aldeamento de indígenas 'nos distritos onde existirem hordas selvagens'. Ora, 'reservar das terras devolutas' significa abstrair destas últimas as ocupadas por "hordas selvagens para sua colonização e aldeamento'. E qual o sentido deste procedimento de discriminação? Lendo o texto, a dedução evidente era para não se levar à venda as terras de ocupação indígena. E no artigo seguinte $\left(\mathrm{n}^{0}{ }^{73}\right)$ especifica-se $o$ procedimento para tanto: 'os inspetores e agrimensores, tendo notícia da existência de tais hordas nas terras devolutas que tiverem que medir, procurarão instruir-se de seu genio e indole, do número provável de almas que elas contêm e da facilidade ou dificuldade para seu aldeamento (...) indicando o lugar mais azado para (seu) estabelecimento (...)'. De posse destas informações, ' (...) o Diretor Geral (das Terras Públicas) proporá ao Governo Imperial a reserva de terras necessária para os aldeamentos' (art. 74)”.

AZANHA, Gilberto. A lei de terras de 1850 e as terras dos índios. Centro de Trabalho Indígena. Disponível em:

https://biblioteca.trabalhoindigenista.org.br/artigos periodicos/a-lei-de-terras-de-1850-e-as-terras-dosindios/. Acesso em 22 nov. 2021.

${ }^{11}$ Sobre a colonialidade do poder, distingue-se do colonialismo, embora seja engendrado nesse processo histórico, refere-se a uma estrutura geocêntrica cultural fundada numa classificação étnica/racial, de gênero etc., que mantém a estrutura de poder no mundo atual. Ver: QUIJANO, Aníbal. Colonialidade do poder e classificação social. In: SANTOS, Boaventura de Sousa; MENESES, Maria Paula (orgs.). Epistemologias do Sul. São Paulo: Cortez, 2010.
} 
serem estrategicamente organizadas, de forma produtiva ou especulativa. A história da formação territorial brasileira tem sido, assim, marcada pelas lutas e violências contra os povos que formam a sociedade.

Moraes (2002), ao formular uma história da Geografia através dos discursos geográficos, que expressam o pensamento hegemônico, buscou desvelar as condições que estruturaram, contraditoriamente, a relação Estado, Sociedade e Território. Acreditamos, contudo, poderia ser, também, fundamental analisar, nas mentalidades vigentes de uma sociedade recém-saída da escravidão, os fundamentos raciais que construíram o território brasileiro. $\mathrm{O}$ território que seria também construído para separar quem é branco e quem não é, espelhando a visão de nação forjada ainda no século XIX, em transição do escravismo para o trabalho livre. Um projeto de branqueamento que se apresentou como modelo de democracia a assimilação de diversos corpos, constituindo hegemonias territoriais, na lógica de um território uno e indivisível, em fins do século XIX, mas que opera sob continuidades moldadas no racismo até hoje.

O Brasil era apontado como um país mestiço - uma nação de raças miscigenadas. Segundo Schwarcz (1993), em Espetáculo das Raças, com a crise da escravidão, o "branqueamento" foi pensado como saída e solução para mais de três séculos de escravagismo que terminava. Essa visão esteve presente entre os viajantes que passaram pelo Brasil e em alguns intelectuais nacionais. Uma imagem veiculada pela interpretação de vários naturalistas que, ao longo do século XIX estiveram no Brasil investigando a fauna e a flora e encontraram "o espetáculo dos homens da mistura de raças". Conforme a autora, as elites importaram e consumiram ideias desenvolvidas na Europa, pois procuravam na raça a explicação para as diferenças entre os povos. Essas ideias serviriam plenamente à formulação de um modelo próprio para o país, uma vez que atendiam ao debate de que a nação e de que tipo de sociedade estava em formação.

A segunda metade do século XIX e o início do século XX caracterizam-se por ser a época áurea do racismo, que tem nas ideias de Gobineau o mote explicativo para a realidade brasileira. Sob a sua interpretação, os brasileiros não seriam dignos de um bom prognóstico, pois acreditava que em menos de duzentos anos essa população seria extinta. Nesse contexto, (SCHWARCZ, 1993, p.35-42) destaca intelectuais, Homens da Sciencia, tais como: Oliveira Viana (IHGB), Tobias Barreto (1839-89), Sílvio Romero (Faculdade de Direito de Recife), João Baptista Lacerda (Museu Nacional), Raimundo Nina Rodrigues (Faculdade de Medicina da Bahia), formulando um genuíno projeto para o Brasil moderno por meio da nação miscigenada, intentando que a continuidade desse processo levaria no futuro a uma nação branca.

Ao longo do século XX, políticas territoriais modernizantes foram colocadas em prática, se inscrevendo no discurso geográfico moderno que consolida o Estado brasileiro. Esforços de centralização política foram realizados, tendo como marco, por exemplo, a fundação do IHGB, em 1838, vislumbrando como um centro de "ilustração nos trópicos" ou o IBGE, em 1936, as superintendências de desenvolvimento regional e os planos geopolíticos de integração territorial, contribuindo a criar uma organização espacial que representasse as aspirações e projetos de modernização brasileira (MORAES, 2002). A abertura de frentes pioneiras em vastas regiões, principalmente, na Amazônia, trouxe inúmeros conflitos indígenas, quilombolas e posseiros que já 
as habitavam. Nos governos militares, a ocupação e (re) organização do território (instalação e disposição/remodelagem de objetos técnicos) integram, com maior rapidez, recursos naturais (fundos territoriais) e, no entanto, seu povo sofreu abandono, violência, tutela ou integração. Na contemporaneidade, a questão ambiental, aponta o autor, sua interface com políticas públicas e a globalização, engendram novos esforços de modernização e tecnificação.

Embora não fale das territorialidades diversas que se debatem no conjunto territorial brasileiro, Moraes nos deixou um legado teórico importante à análise dos movimentos sociais que reivindicam um território frente à persistência de uma visão colonialista de ocupação e exploração dos fundos territoriais. Segundo ele, a história da formação territorial brasileira mostra a exemplo de outras colônias americanas que, após o processo emancipatório, a nova ordem é construída sobre as bases estruturadas no antigo regime, cuja premissa encontrava-se no domínio dos recursos territoriais e na escravidão. No Brasil, tanto a escravidão, quanto o latifúndio e a exploração das riquezas permaneceram centrais na nova ordem social e econômica. A herança escravista e o domínio fundiário influíram na sociabilidade construída:

\begin{abstract}
Nesse quadro de formação nacional tem-se um território a ocupar e um Estado em construção, mas a população disponível não se ajusta à identificação de uma nação conforme os modelos identitários vigentes nos centros hegemônicos. No contexto, ao abandonar-se o caminho da construção da nacionalidade proposto por José Bonifácio (cujo eixo repousava na gradativa abolição das relações escravistas), começa a tomar corpo uma concepção que vai identificar o país não com sua sociedade, mas com seu território. Isto é, o Brasil não será concebido como um povo e sim como uma porção do espaço terrestre, não uma comunidade de indivíduos, mas com um âmbito espacial (MORAES, 2002, p. 116).
\end{abstract}

Os conflitos territoriais no Brasil correspondem, assim, ao embate entre múltiplas e diversas forças sociais que se constituem historicamente sob os fundamentos da modernização do país. Tanto projetos integradores capazes de articular e expandir as forças capitalistas se territorializam, quanto diversas territorialidades se afirmam a partir de desigualdades socioespaciais urbanas e rurais, etnicizando o território. Projetam, dessa forma, suas memórias, identidades, trabalho e história. Simbolismos e concepções que marcam a multiterritorialidade brasileira.

\title{
Territórios étnicos e território brasileiro: considerações finais
}

Nas últimas décadas do século XX, após a promulgação do Art. 68 da Constituição Federal de 1988 (ADCT) ${ }^{12}$, comunidades negras rurais reivindicam o reconhecimento territorial em diversos estados brasileiros. Algumas inquietações se apresentam: que temporalidades se encontram presentes e quais ações repressivas e coercitivas são responsáveis pelos conflitos? quais os mecanismos de resistência e identidades criados por essas comunidades quilombolas? Enfim, quais as suas experiências históricas? Perguntas que podem

\footnotetext{
12 BRASIL. Constituição (1988). Constituição da República Federativa do Brasil: promulgada em 5 de outubro de 1988. "Artigo 68 do Ato das Disposições Constitucionais Transitórias que estabelece: Aos remanescentes das comunidades dos quilombos que estejam ocupando suas terras é reconhecida a propriedade definitiva, devendo o Estado emitir-lhes os títulos respectivos”. Diário Oficial da União, Brasília, DF: Presidência da República, 5 out. 1988.
} 
parecer simplistas, mas que remetem a uma questão no mínimo instigante: onde estavam os quilombolas, estes que estiveram foram de cena na historiografia brasileira, deixando impressão de que junto com a destruição dos quilombos veio o fim da sua história?

Indagações como essas e outras tornam necessária a investigação do processo histórico e geográfico que passa pela resistência ao período escravista à constituição dos quilombos e sua luta pelo território nas atuais comunidades negras rurais e urbanas. Temática que vem sendo pesquisada pelos geógrafos, no sentido de: desembaraçar o emaranhado de fios que formam a malha textual, recuperando, em documentos oficiais, nas falas de mocambeiros; encontrar nas letras de rappers e de relatos de jovens das periferias urbanas, elementos que apontem para as questões de um passado dos mocambos e, num tempo mais recente, da afirmação da identidade quilombola. Compreender a construção dessa identidade étnica e cultural e elementos significativos à definição de um espaço enquanto terra de negros, territórios afrodescendentes, no final das contas, traduz a confrontação da propriedade privada e de reivindicação de políticas públicas. Finalmente, a identificação, demarcação e titulação de terras quilombolas, parecem vir ao encontro da visibilidade, da memória, territorialidade e pertença no cenário da formação brasileira.

O território pode ser assim pensado na dinâmica do conflito, o qual demanda estratégias em face da ameaça à vida, cultura, linguagens, identidades e ancestralidades. Os quilombos têm na oralidade e na memória dos mais velhos as riquezas guardadas no momento da demanda territorial. Barth (2000), contudo, alerta para não pensarmos a cultura de forma estática, mas como elástica, pautando fechamento e abertura, incorporação e exclusão, podendo contrastar quem é de fora com que é de dentro, assim, construindo, desfazendo e reconstruindo as fronteiras. $\mathrm{O}$ território tem relação com essa dinâmica, sendo a territorialidade a expressão das aberturas e fechamentos.

Embora a centralidade do território e da cultura estejam na ordem da análise das identidades autodefinidas quilombolas, segundo Santos (2000), é a totalidade social constituída pelo território nação que engendra as múltiplas temporalidades e espacialidades. Frações de exclusões, gestão dos recursos do território, mercado, disputam na ordem social moderna que contempla as vicissitudes, lutas e conquistas no território, enquanto amparado pelos dispositivos políticos, jurídicos, sociais e econômicos. Assim, o Estado-Nação é capacitado ao reconhecimento dos direitos sociais; é, no entanto, na incompletude da democracia brasileira que se encerram e se ampliam os diversos conflitos envolvendo tantos sujeitos e seus territórios perdidos e reivindicados.

A urbanização, como síntese da totalidade social, sob as diferentes formas: condomínios fechados e agronegócio, o turismo e estruturas técnico científicas, implica em conflitos com a presença de forças múltiplas e dinâmicas advindas da expansão do capitalismo global sob a organização neoliberal. Passa-se às perdas de direitos e inseguranças e à violência que se impõe às lutas sociais contemporâneas, trazendo como dinâmica central o enfraquecimento de direitos conquistados.

No processo da formação da RM de Sorocaba, analisamos que se reproduzem os fundamentos da propriedade privada, mecanismo pelo qual, desde a abolição, os libertos não terão acesso à terra e ao território; nem em São Paulo, Sorocaba ou no restante do país. Identificar as aquisições e fragmentações 
de terras e territórios na região de Sorocaba se apresenta como caminho para entender, tanto as doações de terras a escravos, quanto as perdas que ocorreram à medida em que o mercado de terras e a urbanização do território se tornam central para a reprodução da riqueza.

No cerne dessas discussões, podemos refletir que a vida no território é mais do que o esquadrinhamento espacial do Estado em relação ao domínio do território e da sociedade, mais que o mercado e as redes territoriais formadas para a sua concretização, mas, também, é a vida que estabelece relações próprias e dinâmicas com o território. O processo de territorialização é relativo a territórios de pertencimento construídos pelos sujeitos diversos em diferentes regiões e tempos históricos. Segundo Almeida:

O processo de territorialização é resultante de uma conjunção de fatores, que envolvem a capacidade mobilizatória, em torno de uma política de identidade, e um certo jogo de forças em que os agentes sociais, através de suas expressões organizadas, travam lutas e reivindicam direitos face ao Estado. As relações comunitárias neste processo também se encontram em transformação, descrevendo a passagem de uma unidade afetiva para uma unidade política de mobilização ou de uma existência atomizada para uma existência coletiva. A chamada "comunidade tradicional" se constitui nesta passagem. O significado de "tradicional" mostra-se, deste modo, dinâmico e como um fato do presente, rompendo com a visão essencialista de terras de quilombos, terras indígenas, "babaçuais livres", "castanhais do povo", faxinais e fundos de pastos: fixidez de um território, explicado principalmente por fatores históricos ou pelo quadro natural, como se a cada bioma correspondesse necessariamente uma certa identidade. A construção política de uma identidade coletiva, coadunada com a percepção dos agentes sociais de que é possível assegurar de maneira estável o acesso a recursos básicos, resulta, deste modo, numa territorialidade específica que é produto de reivindicações e de lutas. Tal territorialidade consiste numa forma de interlocução com antagonistas e com o poder do estado" (2008, ps. 118 e 119).

Passado mais de um século, a análise geográfica torna-se ainda mais pertinente num momento em que as políticas neoliberais avançam sobre cidadanias incompletas e ameaçam os direitos conquistados.

\section{Referências}

ALMEIDA, Alfredo Wagner Berno de. Terra de quilombo, terras indígenas, "babaçuais livre", "castanhais do povo", faixinais e fundos de pasto: terras tradicionalmente ocupadas. In: Coleção "Tradição e ordenamento jurídico", vol. 2 projeto nova cartografia social da Amazônia. 2008. Disponível em: https://www.ppgcspa.uema.br/wp-content/uploads/2017/o7/Alfredo-WagnerB-de-Almeida Terras-Tradicionalmente-Ocupadas.pdf Acesso em 20 jun. 2021.

ALMEIDA, Alfredo Wagner Berno de. Processos de Territorialização e Movimentos Sociais na Amazônia. In: OLIVEIRA, Ariovaldo U. de.; MARQUES, Marta Inez Medeiros. O Campo no Século XXI. Território de Vida, de Luta e de Construção da Justiça Social. São Paulo: FINEP/USP/Agrária/Paz e Terra/Casa Amarela, 2004. 163-172. 
ANDRADE Fo. Sílvio Vieira de. Um Estudo sociolinguístico das comunidades negras do Cafundó, do antigo Caxambu e de seus arredores. Sorocaba, SP: Prefeitura Municipal: SEC, 2000.

AZANHA, Gilberto. A lei de terras de 1850 e as terras dos índios. Centro de Trabalho Indígena.

Disponível

em:

https://biblioteca.trabalhoindigenista.org.br/artigos periodicos/a-lei-deterras-de-1850-e-as-terras-dos-indios/. Acesso em 22 nov. 2021.

BACELAR, Carlos de Almeida. Desbravando os sertões paulistas, séculos XVI a XIX. In: GONÇALVES, Paulo Cesar, OLIVEIRA, Lélio Luiz de.; MONTH SERRAT, Pablo Oller. Dossiê: História Da Colonização Em Terras Paulistas: Dinâmicas e Transformações (Séculos XVI a XX). História (São Paulo), v.39, 2020. Disponível

em: $<\underline{\text { https://www.scielo.br/i/his/a/kgcsKMb4LnN9KJvLGj6Ysbr/?lang=pt\&forma }}$ $\underline{\mathrm{t}=\mathrm{pdf}>}$. Acesso em 07 jul. 2021.

BARTH, Fredrik. O guru, o iniciador e outras variações antropológicas. Trad.: John Cunha Comerford. Rio de Janeiro: Contracapa, 2000.

BRASIL. Constituição (1988). Constituição da República Federativa do Brasil: promulgada em 5 de outubro de 1988. "Artigo 68 do Ato das Disposições Constitucionais Transitórias que estabelece: Aos remanescentes das comunidades dos quilombos que estejam ocupando suas terras é reconhecida a propriedade definitiva, devendo o Estado emitir-lhes os títulos respectivos". Diário Oficial da União, Brasília, DF: Presidência da República, 5 out. 1988.

Decreto n. 4.887, de 20 de novembro de 2003. Regulamenta o procedimento para identificação, reconhecimento, delimitação, demarcação e titulação das terras ocupadas por remanescentes das comunidades dos quilombos de que trata o art. 68 do Ato das Disposições Constitucionais Transitórias. Diário Oficial da União, Brasília, DF: Presidência da República, 21 nov. 2003.

CARLOS, Ana Fani A. O espaço urbano: novos escritos sobre a cidade. São Paulo, Contexto, 2004.

CARRIL, Lourdes de F. B.; BURGOS, Rosalina. Espaço público e lugares de memórias negras: (des)encontros entre sujeitos e o patrimônio histórico urbano. Boletim Paulista de Geografia, $\mathrm{n}^{0}$ 104, jul.-dez. 2020.

Quilombo, Favela e Periferia. A longa busca da cidadania. São Paulo: Annablume, 2006.

CORREA, Dora Shelard. Paisagens Sobrepostas. Índios, Posseiros e Fazendeiros nas Matas de Itapeva (1723-1930). Londrina, PA: eduel, 2013.

GOMES, Flávio dos Santos. Mocambos e Quilombos. Uma história do campesinato negro no Brasil. São Paulo: Claro Enigma, 2015.

HAESBAERT, Rogério. Viver no Limite. Território e multi/transterritorialidade em tempos de in-segurança e contenção. Rio de Janeiro: Bertrand Brasil, 2014. 
HAESBAERT, Rogério. Dos Múltiplos Territórios à Multiterritorialidade. Conferência "Dos múltiplos territórios à multiterritorialidade". In: I Seminário Nacional sobre Múltiplas Territorialidades. Programa de Pós-Graduação em Geografia da UFRGS, Curso de Geografia da ULBRA e AGB-Porto Alegre, em 23 de setembro de 2004. Disponível em: https://www.ufrgs.br/petgea/Artigo/rh.pdf. Acesso em: 08 nov. 2021>.

ITESP - Relatório Técnico Científico (RTC) sobre os Remanescentes da Comunidade de Quilombo “Tenente Antônio de almeida Leite”. Fazenda Pilar/Pilar do Sul-SP. ITESP, setembro 2007.

LEFEBVRE, Henri. O direito à cidade. São Paulo: Centauro, 2001.

LENCIONI, Sandra. Cisão Territorial da Indústria e Integração Regional no Estado de São Paulo. In: GONÇALVES, M. F.; BRANDÃO, C. A. \& GALVÃO, A. C. Regiões e Cidades, Cidades nas Regiões. O desafio Urbano-Regional. SP: UNESP/ANPUH, 2003. p. 465-475.

MAIA, Doralice Sátyro. A ferrovia nas cidades bocas de sertão Alterações na morfologia e na estrutura urbana. Terra Brasilis (Nova Série), 8 | 2017. Disponível em: < https://journals.openedition.org/terrabrasilis/2160> . Acesso em: 10 nov. 2021.

MORAES, Antônio Carlos Robert de. Território na Geografia de Milton Santos. São Paulo: Annablume, 2013.

MORAES, Antônio Carlos Robert de. Território e História no Brasil. São Paulo: Annablume/Hucitec, 2002.

QUIJANO, Aníbal. Colonialidade do Poder e Classificação Social. In: SANTOS, Boaventura de Sousa.; MENESES, Maria Paula (orgs.) Epistemologias do Sul. São Paulo: Cortez Editora, 2010. p. 84-131.

RAFFESTIN, Claude. Por uma geografia do poder. São Paulo: Ática, 1993.

SANTOS, Milton. A Natureza do Espaço. São Paulo: Hucitec, 1996.

SCHWARCZ, Lília Moritz. O Espetáculo das Raças. Cientistas, Instruções e Questão Racial no Brasil - 1870-1930. São Paulo: Companhia das Letras, 1993.

SPÓSITO, Eliseu Savério. O novo mapa da indústria no início do século XXI [recurso eletrônico] - São Paulo: Editora da Unesp Digital, 2015. Recurso digital Formato: ePub.

VIEIRA, Eliseila de Goés. Associação dos Remanescentes do Quilombo do Espólio do Tenente Antônio de Almeida Leite da Fazenda Pilar. Especialização (Sociologia). Secretaria de Educação do Governo do Estado de São Paulo/Universidade de São Paulo, 2012.

VOGT, Carlos; FRY, Peter. A África no Brasil. Cafundó. São Paulo: Companhia das Letras, 1996. 
Sites

Blog Quilombo do Pilar. A verdadeira história do quilombo de Pilar do Sul. segunda-feira, 10 de dezembro de 2012. Disponível em: https://quilombodopilar.blogspot.com/. Acesso em: 29 out. 2021. 